\title{
Aligning Teaching and Assessment to Course Objectives: The Case of Preparatory Year English Program at King Abdulaziz University
}

\author{
Rania Kabouha (Corresponding author) \\ English Language Institute, King Abdul-Aziz University, Jeddah 21589, P.O. Box 80200 \\ Kingdom of Saudi Arabia \\ E-mail: raniakabouha@gmail.com \\ Tariq Elyas \\ Faculty of Arts \& Humanities, European Languages Department, King Abdul-Aziz University, Jeddah 21589, P.O. Box 80200 \\ Kingdom of Saudi Arabia \\ E-mail: telyas@kau.edu.sa
}

Received: 17-01- 2015

Published: 01-09- 2015
Accepted: 25-03- 2015

doi:10.7575/aiac.ijalel.v.4n.5p.82
Advance Access Published: April 2015

URL: http://dx.doi.org/10.7575/aiac.ijalel.v.4n.5p.82

\begin{abstract}
This research paper discusses the concept of constructive alignment theory (Biggs, 1996) with the learning outcomes in teaching of English at a Saudi university. The Saudi context has received no empirical attention in the professional literature. Thus, this paper uses constructive alignment framework to examine the Foundation Year English Program (FYEP) curriculum at King Abdul-Aziz University, Saudi Arabia. More specifically, one of the major components of this program, namely, the speaking course, was used as an example to evaluate the extent to which intended learning outcomes, assessment practices, and teaching methods are aligned in this course. It should be mentioned that the 104 speaking course has been selected as an example for two main reasons, which will be discussed in the paper. Therefore, some suggestions are provided to help solve this issue constructively. The paper also highlights the importance of using the constructive alignment framework to enhance teaching, learning, and assessment in English Language Institute (hereafter ELI).This paper is divided into four sections. Following the introduction, it reviews the existing literature on the notion of constructive alignment theory and its pedagogical outcomes in EFL instruction. It then briefly describes the ELI English program and pinpoints the incongruity between the program objectives and the intended learning outcomes. The second section focuses on analysis of the components of the speaking course through Constructive Alignment Framework. The next section identifies some factors, which negatively affect the speaking course. The last section of this paper discusses the implications of constructive alignment for learning and teaching in ELI.
\end{abstract}

Keywords: Constructive Alignment Framework, EFL Instruction, Objectives, Learning Outcomes, Saudi Arabia, EFL, English Language Institute

\section{Introduction}

Constructive alignment theory (Biggs, 1996), by and large, is "one of the most influential ideas in higher education" (Biggs \& Tang, 2007: 11). The basic principle of this concept is that the curriculum should be designed in a way that the learning activities and assessment tasks are aligned with the learning outcomes that are intended in the course of study (Biggs, 2003). It has been argued that using such alignment in English as a foreign language (hereafter EFL) programs would help language educators to "get students actively involved and assess them in ways that enhance the quality of learning" (White, 2012, p.25). According to Tambini (1999) language instructors should design their lesson plans in such a way that instructional objectives, learning and teaching activities, and assessment strategies employed in evaluating students learning are well aligned with one another.

Constructive alignment is a theory of motivation and of planning which looks at teaching far beyond what goes on in the classroom (Brabrand, 2007). Therefore, it should be the starting point when designing a language course, or a learning module that is based on what students should know and be able to demonstrate at the end of a particular course. If there is a mismatch between teaching and assessment, this will have a negative impact on learning, or "when there is alignment between what we want, how we teach and how we assess, teaching is likely to be much more effective than when there is not" (Biggs, 2007, p.6). Teachers should ensure that the assessment improves the process of learning and teaching. For instance, when the lesson is aligned, higher cognitive processing will be required and thus the assessment exercises will similarly require higher order thinking skills and not simple recall of information (Biggs, 2003, p.2). Biggs (2009) argues that an effective educational system is a one in which all aspects of teaching and assessments are integrated to support high-level learning; therefore, all learners are encouraged to use high-order learning processes. 
Much has been said about the effectiveness of using constructive alignment in various domains. Nevertheless, studies on using constructive alignment to evaluate EFL programs are scarce. That is to say, there are few studies that have, specifically, attempted to use constructive alignment framework in order to evaluate whether there is an alignment between what is being taught, learned, and assessed in a language program (e.g., Tambini, 1999; White, 2012; Chua, 2013). Worst still, the Saudi context has received no empirical attention in the professional literature.

\section{Literature review}

Learning takes place in a complex environment; there are many factors interacting within this system such as students` characteristics, teaching methods, curriculum, the learning objectives, and the institutional setting (Shuell, 1986). If there is an imbalance in the system, it will be resolved, and for many students this will often result in a surface approach to learning. If teachers want students to focus on understanding meaning, on developing high level cognitive skills like analysis and synthesis, then the learning activities that teachers design and assessment tasks have to be consistent with those objectives (Shuell, 1986).

In an effective education system, all elements work to foster the goal of meaningful learning.. When there is consistency between what educators want students to learn, how they teach, and how they assess students' academic performance, teaching will be much more productive than when there is the lack of alignment (Shuell, 1986). Professor John Biggs (1996) proposed the concept of "constructive alignment" to describe this consistency. Biggs suggests that conventional teaching methods such as the lecture, tutorial and private individual study do not offer much support for the development of the skills required for higher-level learning processes. Postmodern students cannot only be taught the facts of science. Nevertheless, learners have to reflect on their own cognitive, attitudes, emotions, experiences, and knowledge. Thus, education is about conceptual construction (Dames, 2012).

Biggs ' notion of constructive alignment provides a useful framework for constructing learning by aligning teaching, if students are to achieve desired outcomes such as developing functioning knowledge or professionally relevant understanding (Biggs, 2003). The approach facilitates active students' engagement in authentic learning activities that are designed to achieve desired learning outcomes and assessment in terms of what students can do, rather than the declarative knowledge or knowing about information, they can recite or write (Biggs, 2003). In EFL classrooms, students can benefit from this kind of activities. They need to be actively involved in building up their knowledge of the target language through the use of authentic interactional tasks in a meaningful conversational environment. Correspondingly, thissituation can motivate students to take more control over their own learning, thus fostering a move toward greater learners` autonomy.

Figure one illustrates the underlying principles of constructive alignment, adapted from Biggs (2003). The constructive component suggests that students construct meaning through relevant and authentic learning activities. It implies that it is the responsibility of the teacher to act as the catalyst that facilitates the learning of the students through creating learning activities and assessment that are aligned with the learning outcomes, in such a way that students can construct meaning in a given learning event. That is, it is what the student does that is important in determining what students learn than what the educator does (Biggs, 2003). The alignment component refers to what the educator does. That is, the educator creates a leaning environment that includes learning activities and assessment that can help the studentsto achieve the desired learning outcomes.

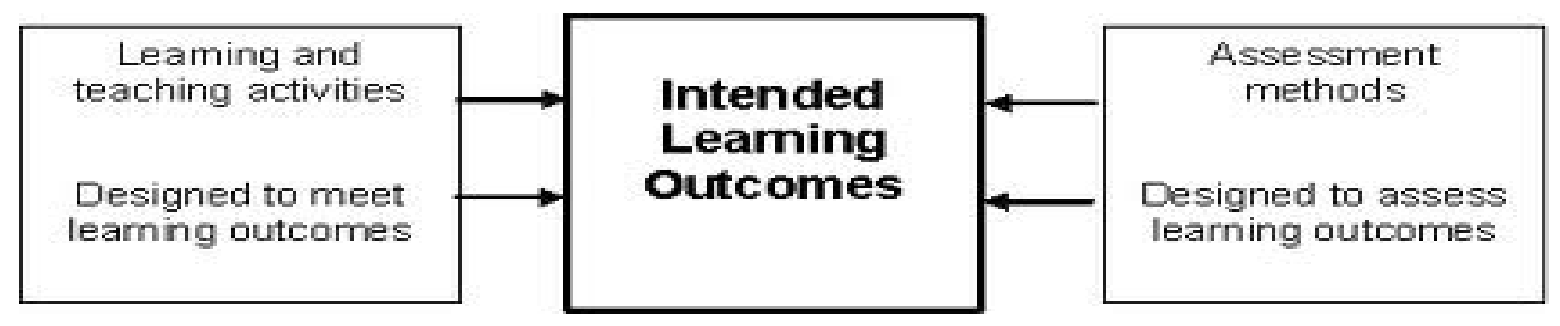

Figure 1. Aligning learning outcomes, activities and assessment

Therefore, constructive alignment is a teaching system aimed at supporting learning, where the emphasis is on process rather than content (Harden, 2002). Biggs (2009) contends that many educators focus on theoretical, declarative knowledge, which results in a surface approach to learning. Consequently, learners concentrate on passing the course without any underlying comprehension of the subject matter. Alternatively, Biggs (2009) highlights the importance of functioning knowledge, which extends the declarative knowledge into a specific context and can include integration of several domains of cognition. The goal is to establish meaningful linkages with learner experience and in promoting connections among knowledge, skills, and experience (Clark, 2011).

Dames (2012) emphasized another important aspect of the theory, he believes that constructive alignment cannot be achieved or maintained in an institutional system that does not allow frequent modification of module descriptions. This highlights the fact that learning is a lifelong process. Therefore, students need to become lifelong learners who are empowered to access information and continually construct their knowledge throughout their lifetime.

Constructive alignment also represents merging of constructivism and instructional design (Lawrence \& Snyder, 2009). Constructivism is based on the belief that learners are at the center of the learning situation, and they are constructors of 
their own learning. Constructivism is the dominant theory of the last decade and supports construction of knowledge by the individuals. "Constructivist instructional design aims to provide generative mental construction "tool kits" embedded in relevant learning environments that facilitate knowledge construction by learners" (Karagiorgi \& Symeou, 2005). The construction of this knowledge is based not only on the types of teaching and learning activities; but on what a student brings to the learning environment, such as prior knowledge, experience, attitudes, and on assumptions (Biggs, 2003). Constructivism provides a framework for thinking about how people learn and how teachers can meet the challenge of finding ways to design instruction that puts constructivist principles into practice (Lawrence \& Snyder, 2009).

In addition, the notion of deep learning strongly resonates with the constructive alignment theory (Biggs, 2009). Teaching that induces surface learning does not produce effective learning as it is based on memorizing and regurgitation, and that teaching needs to encourage deep learning; constructive alignment can help in implementing the concept of deep learning. Deep learning also involves the critical analysis of new ideas, linking them to already known concepts and principles, "it leads to understanding and long term retention of concepts, so that they can be used for problem solving in unfamiliar concepts" (Lawrence \& Snyder, 2009,p.27).

Tambini`s (1999) study discussed the application of constructive alignment principles within the context of a lesson plan in an ESL classroom. The class for which this lesson plan was developed was a part of an Intensive English Language Program at Centenary College in New Jersey, USA. He claimed that the alignment of performance standards, instructional objectives, and assessment strategies is necessary to achieve an accurate evaluation of students' academic performance. He found that this alignment was possible within the context of a single lesson plan, he said " It has been successfully achieved: students are given the opportunity to learn, the teacher is provided effective means to gauge that learning, and communication between students and teacher is encouraged and supported" (Tambini, 1999,p.3).

According to Dames (2012), curriculum themes should be defined in terms of outcome statements in addressing both the teaching and the learning activities (TLAs) and assessment tasks (ATs). He maintained that most of universities` courses foster inappropriate learning activities (LAs)which are unaligned and lead to a surface approach in learning. Constructive alignment is designed to foster practical knowledge and deep learning instead (Dames, 2012). Constructive aligned teaching systematizes the planning and activities of teaching activities. It results in open - ended assessment tasks, which allow for unintended, but desirable outcomes (Biggs \& Tang, 2009).

Chua (2013) examined the effectiveness of constructive alignment and experiential learning in her study of the English language program for foundation year students at Jubail University College (JUC), Female Branch, in the Kingdom of Saudi Arabia (hereafter KSA). She concluded that, "students developed critical thinking, problem-solving, active and reflective use of knowledge. Aligning to curriculum, instruction, and assessments can possibly be done" (Chua, 2013, p.244). Chua (2013) indicated that there are many ways of improving language-teaching methods, strategies, instructional materials when educators are ready to embrace a constructively aligned teaching and learning.

On that account, this concept should be considered as an essential tool for examining the coherence between instructional strategies, learning activities, and assessment procedures with the intended learning outcomes in an existing language program. Accordingly, this harmony will ensure an internally consistent structure that can facilitate the vision of high quality language teaching and learning (Chua, 2013).

The next section of this paper focuses on a brief description of the Foundation Year English language program at KAU to examine the program in consideration of constructive alignment principles.

\subsection{Description of the language program in ELI}

Over the past four years, the ELI has witnessed different shifts and transformations with the aim of withdrawing from traditional teacher-centered approaches, towards more humanistic, socio-cultural, and leaner-centered approaches in language learning and teaching. The language program in ELI "provides general English language courses to over 12,000 male and female full-time KAU Foundation Year students annually"(the English Language Institute, King Abdul-Aziz University [ELI-KAU], 2013). The ELI has developed it's so - called mission statement, which implies the general aim of the program that is to provide intensive instruction of English as a foreign language, to preparatory year students in order to improve their English language skills and facilitate their academic progress. The program curriculum is comprised of four core language courses, designed to improve students' English language skills, so they can cope with the demands of higher education. In addition, the program provides training in the four-macro skills of English language instruction: reading, writing, listening, and speaking. There is a set of objectives, which the ELI is striving to achieve. One of the major objectives of the program, as stated in the ELI official website, is "to help students of the Foundation Year to achieve an Intermediate Level of proficiency in the use of the English language, equivalent to the Common European Framework Reference of B1 Threshold Level (CEFR B1)"(ELI -KAU, 2013).Another important objective is building students' confidence by providing them with opportunity to interact in the classrooms, and making their language learning experience enjoyable, purposeful and meaningful.

At the beginning of each module, faculty members are provided with detailed curriculum syllabi with expected learning outcomes for courses they are assigned to teach at the ELI. Moreover, teachers are given a detailed Pacing Guide for each course containing day-to-day lesson planning guides. This details exactly how many textbook units and language items are to be presented and practiced during a specified time-frame (seven weeks). 
In theory, the students are educated according to their abilities and their scientific and academic interests, or as the director of the ELI stated "The core curriculum of the English language intensive course prepares students for a number of professional majors and helps them to play a successful role in society". However, in reality, there is a tremendous pressure on the students who have to pass the prescribed assessments and examinations within a limited period of time. Unfortunately, students are neither able to engage in an oral communication with English speakers nor able to write coherent and cohesive essays. Moreover, the great majority of students are able to produce only a few memorized correct English sentences, and they generally have no opportunity to practice English outside the classroom. Undoubtedly, there is a clear incongruity between the course objectives and the learning outcomes. Thus, from a constructivist perspective, the program fails to give clear and consistent signals about what it is important to learn and how it should be understood (Nightingale, Carew, \&Fung, 2007).This paper analyzes the main components of the 104speaking course in ELI in view of the notion of constructive alignment.

\subsection{Analysis of ELI 104 speaking course in light of Constructive Alignment Framework}

Effective teaching is designed to provide students with increased choice, personalization and assessment activities that are carefully designed to be consistent with desired learning outcomes, and which coherently connect learning theory, the curriculum, classroom activities and assessment (Clark, 2011). This is highly compatible with the concept of constructive alignment and its key concepts. According to Biggs (2003), Constructive Alignment has two aspects: the constructive aspect and the alignment aspect. The constructive aspect relates to what the learner does in order to construct meaning through appropriate, purposeful, relevant, authentic and meaningful learning activities. The teacher's role is reduced to being the catalyst, a facilitator for the learning of the student through creating learning activities and assessment tasks that are aligned with the learning outcomes, in such a way that students can construct meaning in a given learning event.

However, the alignment aspect refers to what the teacher does, structuring a learning environment that supports the learning activities and opportunities appropriate with achieving the desired learning outcomes. The teacher also needs to promote higher order thinking skills and understand what the students think of learning and how they approachthe learning process.After this stage, the teacher needs to design assessment methods that suit the students' conceptions and approaches to learning. This means that the system is consistent and all aspects of the system are in accord in supporting appropriate student learning (Biggs, 2003).

Nevertheless, the process is by far more complex. Biggs (2003) believes that constructive alignment is actually extremely difficult to achieve, teachers should constantly reflect on the course design and delivery; he even goes further to claim that constructive alignment cannot be accomplished or maintained in an educational system that does not allow for frequent adaptations of module descriptions. Sometimes, in the delivery of a module, assessment outcomes, or our work with students, reveal learning outcomes we had not anticipated, but that we recognize as valuable. These emergent learning outcomes need to be identified and incorporated into the intended learning outcomes (Biggs, 2007). Therefore, instructors should regularly seek compatibility between teaching and learning activities, curriculum objectives and assessment procedures. The alignment of these three key areas can be achieved following the $3 \mathrm{P}$ model described by Biggs (2009): presage, process and product.

In ELI, all three stages are incomplete, hence the failure to achieve the desired learning outcomes. Presage is the first stage before learning occurs. It includes learners' prior knowledge and experience, what they bring into the classroom, what it is intended to be taught, how it will be taught and assessed, and the expertise of the teacher. Thus, teaching must be organized with a focus on the individual student's learning process, emphasizing a high degree of student activity and a low degree of traditional teacher centered teaching. Unfortunately, in ELI the students are treated astabula rasa. They are mere receptors of prescribed information passed to them without providing a reason for any given learning activity, absorbing information and storing it in their minds. Most of the interactions are between the teacher and students, but there is very little communications between the students. This is the most important stage of planning the process of teaching and learning. It is the beginning of the learning experience and teachers should devote more time to planning an accurate teaching and assessment system, fit for the purpose and course objectives. Nonetheless, this stage is hindered by time constraints, as the teachers have to finish and wrap up the course within a limited time- frame (seven weeks). This situation forces the teachers to follow traditional lecture classes, eliminating many communicative activities and practices that can help develop students' language proficiency. Therefore, teaching English as a finish product rather than a developing process.

The next stage is called the process, and it takes place in the classroom during the learning process. This stage includes all the learning focused activities and tasks when the teacher should act as a facilitator. The students are expected to construct meaning and take responsibility for their learning. However, a typical English lesson in ELI restricts and controls teachers' choices in terms of teaching approaches and strategies, as they have to closely follow the textbook. What should have been a blend of four skills in the classroom, it is in fact a focus on reading and writing while little attention is paid to speaking skills. Moreover, teachers explain linguistic structures, rather than encouraging oral use of the language. As a result, students depend on rote-learning and memorizing rather than using language creatively or contextually at the expense of language use in real life purposeful and meaningful communication situations. In addition, the skills are manipulated linguistically rather than communicatively, and there is few opportunities for a real and free conversational exchange between teachers and students and very little between students. Many ELI instructors still adhere to the notion that language learning involves a quantitative increase in the knowledge of English vocabularies and grammatical rules, assuming that this understanding will help them in gradually acquiring the 
language and fostering fluency. However, following the textbook activities without making any changes to the materials to be delivered hinders the effectiveness of this stage.

Finally, the product stage, which can be defined as the accomplishment of the desired learning outcomes, or in our context, absence of it to a certain extent. Students are often incapable to speak freely and spontaneously because they do not usually practice speaking inside or outside of the classroom. The speaking tasks, which students carry out in the classroom, take the form of controlled role-play, chain drill, or question-and-answer exercises. These activities cannot be considered as authentic communicative activities, that resemble the natural interactions in the real world, "authentic learning occurs when instruction is designed to facilitate, simulate and recreate real-life complexities and occurrences" (Karagiorgi \& Symeou, 2005, p.20).

Another significant aspect of the program that requires modifications is the speaking objectives. The objectives are not reliable or definite as they not only lack specificity and clarity, but they are also open to multiple interpretations. For instance, one the course objectives for level four states that "students should give a straightforward talk, participate in extended oral communications on familiar topics, and convey meaning with reasonable precision"(ELI-KAU, 2013). Clearly, the instructional objectives are unrealistic. Moreover, they are not stated in terms of behavioral representations of students' actions and outcomes. They are superficial, general and sometimes vague and do not produce competent English users. The lack of specific objectives should be regarded as a major problem and should be taken into consideration by the policy makers and curriculum designers (Al-Subahi, 2001).

The speaking test in ELI takes the form of an oral interview between the student, the class teacher, and the examiner. The teacher usually provides students with some speaking tasks that nearly resemble the final speaking exam, which often takes place at the end of the module. Consequently, students memorize the content of these class activities in preparation for the speaking test. The speaking activities students carry out in the classroom restrict their output and language production. According to Morrow`s study (as cited in Freeman, 2003), communicative activities have three characteristics in common: information gap, choice, and feedback. An information gap exists when one person in an exchange knows something the other person does not know. In real-life communications, the speaker has a choice about how to communicate his message (meaning and structures). If the exercise is controlled, in which students can answer in only one way, using a particular form; then the interaction is not a real communication. In addition, a real communication has a purpose, the speaker can evaluate whether or not his or her purpose has been achieved based on the feedback received from the listener. If the speaker does not receive feedback from the listener, the exchange will not be communicative. Unfortunately, none of the three features exists in any of the speaking tasks ELI students perform in the classroom. The students' interactions are tightly controlled in terms of content and forms. Therefore, learners will not be able to transfer what they learn inside the class to the outside world. Consequently, students will be limited in their ability to engage in extended oral communication. If instructors only ask their students a limited range of questions, students will not be able to show what they know or make links to what the instructor is teaching (Biggs, 2009).

\subsection{Factors affecting the speaking course in ELI}

As far as the speaking assessment is concerned, there are a few aspects worth mentioning as they affect students' learning and performance negatively. One of critical factors is the time restrictions for answering the tasks in the speaking exam, which may put students under pressure and drive them to work on exam techniques, not demonstrating their full understanding or developing deeper learning of the material(Nightingale, Carew, \&Fung, 2007). The assessment of students' progress and achievement in EFL/ ESL classroom should be carried out in a manner that does not cause anxiety in the students (Shaaban, 2001). Secondly, the alignment between stated learning objectives and assessment tasks is problematic. There is little emphasis on making learning objectives explicit to the students. Teachers need to devote time in class to clearly explain to students what is expected from them; learning takes place when it is clear to students what the objectives are and where they are supposed to be going(Lawrence \& Snyder, 2009). In addition, there is not any kind of interaction between students in the classroom. Teachers should provide opportunities for students to practice speaking and communicate with each other inside the classroom in order to achieve or meet criteria for performance in the speaking test. Thirdly, scoring is broadly designed and focused on task completion of the test takers, but it does not refer to how well the students performed linguistically while completing the task, which should actually be the purpose of testing. Moreover, the speaking test offers limited choice of tasks and it requires students to offer a subjective answer. Furthermore, the marking scale for the speaking tests contains broad descriptors to be assessed. Thus, this presents a challenge to the examiners to understand the principle behind the particular rating scales they must work with, and to be able to interpret their descriptor competently (Alderson, Clapham, \& Wall, 1995).The difficulty in interpreting the assessment rubric can increase the element of subjective judgment in evaluating learners` answers. As well as, the lack of standardization procedures prior to commencing marking properly might lead to unreliability in marking.

In addition to all the above mentioned factors, excluding teachers from taking an active role in the process of designing course syllabi, assessment tasks, course materials, and exams is a critical issue in ELI that requires urgent consideration. In all academic settings, the assessment is viewed as closely related to instruction (Shaaban, 2001). Assessments help teachers make decisions about students` linguistic competence and their achievements. The success of any assessment depends on "the teacher's effective selection of learning tools and proper interpretation of students ' performance" (Shaaban, 2001, p.2). Unfortunately, In ELI, the program coordinators and administrators are the ones who design the courses syllabi, tests, and assessment tasks, which is another factor that negatively influences the effectiveness of the 
speaking course. Teachers have no role in this process; they simply receive these documents at the beginning of the module and closely follow them without any adaptations or adjustments. The case is even worse with the formal tests as teachers have no prior knowledge of the exams' questions until the exam`s day. Marginalizing the teacher's role in this essential process of the language program has a detrimental effect on students' language development

\section{Implications of using constructive alignment in ELI}

The paper concentrates on the opportunity and constraints of using Constructive alignment theory at KAU while trying to offer suggestions and changes that can enhance students learning. Certain factors are taken into consideration even though the list of potential threats to achieving effective learning is not exhaustive: classroom practice and learning activities, learning outcomes, assessment and scoring of the speaking test.

\subsection{Classroom practice and learning activities}

Learning activities should be planned and carried out, so that they match both the course content and the intended learning outcomes. However, a prescribed curriculum to be followed by teachers restricts them from achieving an alignment in learning activities. Teachers focus too much on teaching grammar. Grammar is important, but the knowledge of grammar alone cannot enable students to interact with people in English outside that classroom, students' communicative abilities require improvement, this can be achieved through incorporating activities that are more communicative and engaging in the lessons. In addition, a shift from a focus on grammar to speaking is also needed. Creating more authentic and engaging speaking activities in the classroom, students will be encouraged to regularly practicethe language spontaneously and freely in the classroom with their peers; as a result, students will be able to achieve the desired learning outcomes. Teachers' essential task should be to engage learners in activities that are likely to enable them achieve the desired learning outcomes (Biggs, 2003). Moreover, teachers need to establish situations in the classroom that would promote meaningful interactions between students, for example, pair/group work, problemsolving tasks, and projects. These activities enable students to construct their knowledge of the language in a relaxed and comfortable atmosphere, where students work in collaboration to complete the task. Students then become responsible of their own learning. In this sense, instructors become in charge of coordinating the activities required to facilitate the learning experience and adopting the necessary supportive learning strategies (Shaaban, 2001).Correspondingly, the types of questions students have in the exam will need to change; there should be a few questions that test students' linguistic competence.

\subsection{Learning outcomes}

The lack of clear intended learning outcomes that set out explicitly has led to a mismatch between what it is taught and what it is required from students to achieve. Therefore, more detailed core learning outcomes to which teaching, learning and assessment can be constructively aligned are needed (Harden, 2002b).

It is advisable that teachers make the learning objectives explicit to the students at the beginning of the course. They need to devote time in class and clearly explain what it is expected from them and practice in order to achieve criteria for performance. On a regular basis, the teacher should link the content of the course to the intended learning outcomes so that the students are made aware of the purpose of the learning activities, which they usually carry out in class. They should continuously be encouraged to reflect on their own learning process in relation to the explicit intended learning outcome as well as in relation to specific personal academic interests. When students are provided with this alignment between objectives and learning outcomes, they will be more intrinsically motivated and their performance will be enhanced (Brabrand, 2001).

\subsection{Alternatives in assessment}

Students are assessed at the exam by a summative evaluation of the level at which they demonstrate meeting the intended learning outcomes. Nevertheless, a formative evaluation of students' performance does not take place during the course and the students are not invited to reflect on the status of their own learning in relation to the intended learning outcome. Therefore, the teacher has no instructional methods for adjusting her teaching in order to adapt to the needs of individual students or engage students in the learning activities. Burns (2008) proposes that formative assessment is a critical element in an effective classroom; it is intended to foster development and improvement within an ongoing activity. As ELI program has been moving in the direction of implementing communicative approaches in language teaching and learning, the summative form of testing which "permeated the traditional curricula would not be fair to students whose studies are based on communicative activities" (Shaaban, 2001,p.16).

\subsection{Curriculum design and development}

It is highly recommended that instructors in ELI be authorized and permitted to engage in the process of designing the program curricula. Teachers should be allowed to play a significant role in the process of planning the courses syllabi, assessment tasks, learning materials, and exam questions. Moreover, teachers are encouraged to reflect on their practice at every step of the course. As a result, teachers may find it useful to regularly change and adapt the course syllabus, materials, and assessment tasks in accord with students ' needs. In addition, curriculum developers in ELI need to engage teachers in the construction and planning of the materials of the course as this will enable them to provide students with a well-aligned language program that directly addresses their needs and facilitate their learning. "There is a need to develop and redevelop the teaching and learning materials, the use of learning materials and handouts, compendiums, activities, and the like. Ultimately, the purpose of improving teaching is studying our students ' learning" (Chua, 2013, p.242). 


\section{Conclusion}

Teaching is a very complex and multi-faceted activity and the word can mean very different things in different contexts (Squires, 1999). At KAU, teaching can be challenging, it entails teachers to follow rigid frameworks, influencing thus the quality of teaching and the quality of learning students achieve. As long as there is not a consensus between intended learning outcomes, learning activities and assessment practices, most of the learners will adopt a surface approach to their learning (Prosser \&Trigwell, 1999). Nevertheless, the problem is manifold and requires further investigations. The model of 'constructive alignment' could provide a solution and thus a useful understanding of the process of learning and assessment. Thebasic foundation of constructive alignment is that in a good teaching system the curriculum is designed so that the learning activities and assessment tasks are aligned with the intended learning outcomes in the course (Carpenter, 2008).

Moreover, the implementation of intended learning outcome, teaching and learning activities and assessment forms must be aligned. As a result, students should be made aware of this correlation, so that they achieve the best possible progression and results. In a perfect world without time constraints and institution pressure, teachers would develop the teaching and learning activities guided by the specified assessment standards in the level of understanding that they want the learners to achieve. Hereafter, they would set up an environment in which the learners could be able to be actively involved in the activities designed to achieve the learning outcomes. Lastly, the teachers would develop assessment exercises around the assessment standards that lead towards the attainment of the intended learning outcomes. This means that the delivery of the content and whatever the educator assesses is thus guided by the assessment standards. It is also advisable that instructors continuously reflect on their teaching practices because this will lead to quality learning and teaching, as well as, professional growth. Angelo and Cross emphasizes (as cited in Chue,2013) the current view in higher education is that we should focus on student learning rather than teaching in order to improve students' college experience; this can only happen through implementing constructive alignment in learning and teaching.

\section{References}

Alderson, J.C., Clapham, C., \& Wall, D. (1995). Language test construction and evaluation.Cambridge: CambridgeUniversity Press.

Al-Subahi, A.(2001). Evaluation of the English programme (ESA) at Saudi intermediate school. Journal of KingAbdulazizUniversity, Educational \&Sciences, 14, 3-86.

Biggs, J.(1996). Enhancing teaching through constructive alignment. HigherEducation, 32, 347-364.

Biggs, J. (2003). Aligning teaching and assessing to course objectives. Teaching and Learning in Higher Education: New Trends and Innovations. University of Aveiro, 13-17 April 2003.

Biggs, J. B., \& Tang, T. S. (2009). Teaching for quality learning at university(3rd ed.).Maindenhead: Open University Press.

Brabrand, C.(2007).Constructive alignment for teaching model-based design for concurrency: A case study on implementing alignment. Depart. University of Aarhus, Debmark.

Burns, M.K.(2008).What is formative evaluation? Minnesota Center for Reading Research.

Carpenter, A.(2008). Academics and learners' perceptions of assessment. Institute of Technology Carlow. AISHE Conference August 2008.

Chua, E. R.(2013). Constructive alignment vs experiential learning for ESL students. Arab World Journal, 4 (2), 235245 .

Clark, I. (2011). The Development of 'Project1': Formative Assessment Strategies in UK Schools. Current Issues in Education, 13(3), 1-34.

Dames, G.E.(2012).Enhancing of teaching and learning through constructive alignment. Acta Theologica, 2,3553.doi:http://dx.doi.org/10.4314/actat.v32i2.3

Freeman, D.L.(2003).Techniques and principles in language teaching(2nd ed.).Oxford:Oxford University Press.

Harden, R. (2002b). Learning outcomes and instructional objectives: is there a difference? Medical Teacher, 24, 151155 .

Karagiorgi,Y.,\& Symeou, L.(2005). Translating Constructivism into instructional design: Potential and limitations. Educational Technology and Society, 8(1), 17-27.

Lawrence,B., \& Snyder,L.(2009).Process education and constructive alignment: Thechallenge of student Assessment Online. International Journal of Process Education, 1(1),25-30.

Nightingale, S., Carew, A., \& Fung, J. (2007).Application of Constructive Alignment Principles to Engineering Education: Have we really changed? Proceedings of the 2007 AaeE Conference, Melbourne.

Prosser, M., \&Trigwell, K. (1998). Teaching for learning in higher education. Buckingham:Open University Press.

Shaaban,K.(2001).Assessment of young learners. English Teaching Forum, 39(4),16-24. 
Shuell, T. J. (1986). Cognitive conceptions of learning. Review of Educational Research, 56, 411-436.

Squires, G. (1999). Teaching as a professional discipline. London: Falmer Press.

Tambini, R.F.(1999).Aligning learning activities and assessment strategies in the ESL classroom. The Internet TESL Journal,5(9).Retrieved from http://iteslj.org/Articles/Tambini-Aligning.html)

The English Language Institute, King Abdul-Aziz University. (2013)

White, E. (2012). Are You Assessment Literate? Some Fundamental Questions Regarding

Effective Classroom-based Assessment. Retrieved from http://jaltcue.org/files/OnCUE/OCJ3-1articles/OCJ3-1-Whitepp3-25.pdf.

\section{Appendix}

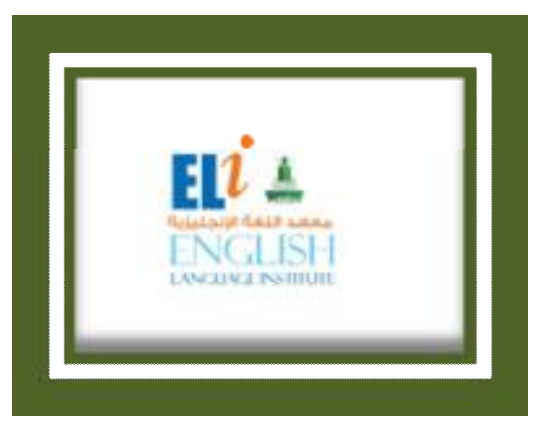

\section{ELI104 Course Syllabus}

Level four has an integrated syllabus, combining the fundamental language skills (speaking, writing, listening, and reading).

Course Title: English Language Level Four

Course Code: ELI 104Course Prerequisite: Successful completion of ELI 103 or an Oxford Online Placement Test score corresponding to pre-intermediate proficiency level.

Credits: There are two credits for this course. Successful completion of ELI 104 gives students the necessary credits to meet the Foundation Year English requirement for securing admission to various undergraduate programs.

Course Description: ELI 104 is an intermediate level course aiming to build and further improve language proficiency at B1 Threshold level on the Common European Framework of Reference for Languages (CEFR). It is a seven-week module course with 18 hours of instruction each week.

Course Goal: The course aims at helping learners to achieve an overall English language proficiency leading to higher Independent User of language defined as high B1 level on the Common European Framework of Reference for Languages (CEFR), giving reasons and explanations for opinions and plans and describing experiences and events.

Course Objectives: The course is intended to accomplish its goal in one full academic module of seven weeks through developing students' language skills to:

1. Read and understand a wide variety of extended texts. (READING)

2. Listen to extended conversations and monologues on a range of topics, identifying both general messages and specific details provided speech is clearly articulated in a familiar accent. (LISTENING COMPREHENSION)

3. Give a straightforward talk and participate in extended oral communications on a familiar topic, be followed without difficulty most of the time, and convey meaning with reasonable precision. (SPOKEN PRODUCTION)

4. Construct coherent and cohesive texts with multiple paragraphs using appropriate vocabulary* in a fully developed response. (WRITING)

5. Use a sufficient range of vocabulary* and grammatical structures to communicate on a range of topics although flexibility may be limited when communicating on less familiar topics. (USE OF ENGLISH)

Student Learning Outcomes (SLOs): See the detailed 104 SLOs document in the ELI Curriculum Guide 2013/2014.

Learner Training: Learner training is essential to the achievement of the Learning Outcomes. It helps learners select and implement appropriate learning strategies and resources, monitor their own use of strategies and change them if necessary, and monitor the effectiveness of their own learning. It covers a range of learner needs including dictionary use, taking notes, vocabulary notebook, questioning, learners' collaboration, learner autonomy, and self-study and revision skills using the Learning Management System (LMS) for online practice. 
Course Materials: The core textbook is Soars, John and Liz, (2011), New Headway Plus Intermediate, Special Edition, Oxford University Press with the following support resources:

- Workbook with DVD-ROM.

- Supplemental Intermediate Speaking Materials.

- Reading Circles Story.

- Supplemental Intermediate Writing Pack for additional writing support.

- Learning Management System (LMS) for online practice at www.headwayplusonline.com accessed with the Student's Access Code found in the back of the Student's Book.

Course Length and Pacing: ELI 104 consists of 18 hours of class time each week. The English Language Institute follows a modular system with two modules taught in each academic semester. Thus, the course length for ELI 104 is one module of seven calendar weeks which allows for a total of 126 hours of class time each module. The 104 Instructor's Pacing Guide is designed on a weekly basis, specifying available materials and providing instructors with a degree of flexibility, allowing ample class time for language practice, and for the incorporation of relevant supplementary materials to facilitate SLO achievement. It also emphasizes regular Learner Training as an essential component of the learning process. http://eli.kau.edu.sa/Default.aspx?Site_ID=126\&Lng=AR

Assessment: Student achievement is measured from a variety of assessment perspectives, including Continuous Assessment (20\%), Computer-Based Mid-Module (20\%), one Speaking Examination (10\%), one Writing Examination (10\%), and Final Examinations (40\%). Continuous Assessment includes Formative Speaking Tasks, Reading Program Tasks, Formative Writing Tasks, and Learning Management System (LMS) Practice. The Mid-Module and Final Examinations focus on listening and reading comprehension, grammar usage, and vocabulary.

The assessment tools are designed and administered as follows:

\section{Continuous Assessment}

- Content: Formative Speaking Tasks, Reading Program Tasks, Formative Writing Tasks, and LMS Practice.

- Format: Supplemental Speaking Materials, Supplemental Writing Materials, Reading Program Graded Readers, and LMS Practice.

- Weight: $20 \%$ of the final grade.

\section{Computer-Based Mid-Module Examination}

- Content: Listening \& Reading Comprehension, Grammar Usage, Vocabulary

- Format: Multiple Choice Questions (MCQs).

- Frequency: One mid-module exam.

- Time: 90 minutes.

- Weight: $20 \%$ of final grade.

\section{Speaking Examination}

- Content: A short talk on a familiar topic.

- Format: A prompted extended turn in front of assessors and a short dialogue with assessors

- Frequency: One per module.

- Time: 5 minutes.

- Weight: $10 \%$ of the final grade.

\section{Writing Examination}

- Content: A coherent and cohesive argumentative essay of at least three paragraphs on a familiar topic, using facts, opinions, appropriate introduction, supporting details, conclusion, and displaying accurate spelling and appropriate grammatical and lexical range and accuracy for this level in legible, neat, and comprehensible writing.

- Frequency: One per module.

- Time: 40 minutes.

- Weight: $10 \%$ of the final grade. 


\section{Computer-Based End-of-Module Examination}

- Content: Listening \& Reading Comprehension, Grammar Usage, Vocabulary

- $\quad$ Format: Multiple Choice Questions (MCQs).

- Frequency: One at end of module.

- Time: 105 minutes.

- Weight: $40 \%$ of final grade.

\section{Disclaimer}

Dates for the examinations will vary each module depending on the University calendar. Exact dates will be announced. Students are expected to present original work in all examinations. Plagiarism or copying the work of others in any form invalidates a test assessment, resulting in no credit or mark for that work. 